\title{
HUBUNGAN LAMA PENGGUNAAN KOMPUTER DENGAN KEJADIAN COMPUTER VISION SYNDROME PADA PEGAWAI KANTOR DI RUMAH SAKIT GRANDMED LUBUK PAKAM
}

\author{
Irmayani ${ }^{1}$, Beny Irawan ${ }^{2}$, Anggi Isnani Parinduri ${ }^{3}$, \\ Atika Sari Lubis ${ }^{4}$ \\ Progaran Studi Kesehatan Masyarakat Fakultas Kesehatan Masyarakat \\ Institut Kesehatan Medistra Lubuk Pakam \\ Jl. Sudirman No.38 Lubuk Pakam Kec. Lubuk Pakam Kab. Deli Serdang, \\ Sumatera Utara \\ Email: irmayaniph06@yahoo.com \\ DOI : https://doi.org/10.35451/jkg.v2i2.393
}

\begin{abstract}
The use of computers increases continuously over time. The average work time used to work with a computer is 5.8 hours or $69 \%$ of the total 8 working hours. Computers that are now widely used as assistive devices can actually cause occupational diseases or health problems. One of them is eye disorders due to continuous use of the eye to stare at a computer monitor or Visual Display Terminal (VDT). This study aims to explain the relationship long use of computers with events computer vision syndrome. This research is a quantitative study with using analytic survey approach with cross sectional design. The population of the research this is the whole employees of offices that exist in Grandmed Hospital Lubuk Pakam. The number of samples taken 36 employees with sampling techniques using total sampling. The collection of data is done by using a questionnaire. Statistical tests using the chi square test with $a=0.05$. The analysis shows that there is a correlation long usege of computer with events computer vision syndrome In employee health BPJS in Grandmed Hospital Lubuk Pakam ( $p=0.004<a=0.05$ ). Suggested to employees of offices if already started to feel fatigue in the eyes and the eyes feel strained should rest and using methods of 20-20-20 is for using the computer in 20 minutes should rest for 20 seconds to switch the view that is within 20 feet to avoid the eyes dry and cause the symptoms are more severe.
\end{abstract}

\section{Keywords: Computer use, computer vision syndrome}




\section{PENDAHULUAN}

Kemajuan teknologi yang pesat menjadikan komputer sebagai alat bantu sehingga membuat pekerjaan dapat diselesaikan dengan cepat dan efisien. Hampir semua bidang pekerjaan saat ini memakai komputer sebagai alat untuk mempermudah pekerjaannnya, ada sekitar 100 juta orang mengggunakan komputer pada pekerjaan mereka sehari-harinya (Izquerdo, 2016). Penggunaan komputerndalam waktu lama dapat menyebabkan stress yang lebih tinggi daripada pekerja lain. Data menunjukkan sebanyak $88 \%$ dari seluruh pekerja yang ada mengalami Computer Vision Syndrome (CVS). Semakin lama durasi paparan komputer setiap hari berbanding lurus dengan banyaknya gejala yang dialami responden pengguna komputer (Akinbinu \& Mashalla, 2014). CVS merupakan istilah untuk menjelaskan berbagai gejala seperti rasa tidak nyaman pada mata, mata kering, rasa tegang pada mata, sakit kepala, penglihatan buram pada jarak dekat, dan penglihatan ganda pada pengguna komputer. Pengguna yang mengeluhkan rasa sakit pada leher dan punggung juga termasuk juga kedalam gejala CVS. Gejala Computer Vision Syndrome terbagi dalam empat kategori yaitu: Gejala astenopia terdiri dari mata lelah, mata tegang, mata terasa sakit, mata kering, dan nyeri kepala. Berdasarkan survey yang dilakukan di Kantor BPJS Kesehatan Lubuk Pakam yang berjumlah 36 pegawai, ditemukan bahwa pegawai kantor bekerja menggunakan komputer sebagai alat untuk menyelesaikan pekerjaannya. Waktu yang digunakan pegawai dalam bekerja menggunakan komputer ratarata 4-5 jam dalam sehari. Berdasarkan hasil wawancara lagsung yang dilakukan kepada sebagian pegawai menunjukkan bahwa pegawai kantor mengalami gejala seperti mata tersa tegang mata kering dan sering mengeluhkan nyeri pada bagian leher. Berdasarkan data dan hasil survei belum ada yang melakukan penelitian tentang Hubungan Lama Penggunaan Komputer dengan Kejadian Computer Vision Syndrome pada pada pegawai kantor bagian BPJS Kesehatan.

\section{METODE PENELITIAN}

Jenis penelitian yang digunakan pada penelitian ini yaitu penelitian kuantitatif dengan pendekatan survey analitik, menggunakan desain penelitian yaitu cross sectional yang bertujuan untuk menjelaskan hubungan lama penggunaan komputer dengan kejadian Computer Vision Syndrome pada pegawai kantor BPJS Kesehatan Lubuk Pakam yang diukur dan dikumpulkan pada waktu yang bersamaan dan dilakukan pada situasi saat yang sama (Sugiyono, 2017). Populasi dalam penelitian ini seluruh pegawai kantor BPJS Kesehatan di Rumah Sakit Grandmed Lubuk Pakam yang berjumlah 36 orang. Pengambilan sampel dengan menggunakan tekhnik Total sampling yaitu seluruh populasi dijadikan sampel. Pengumpulan data dengan menggunakan data primer dan data sekunder. Wawancara kepada responden dengan berpedoman pada kuesioner yang telah dipersiapkan merupakan teknik yang digunakan dalam mengumpulkan data primer. 
Sedangkan data sekunder diperoleh dari bagian HRD di Rumah Sakit Grandmed Lubuk Pakam yaitu data tentang jumlah SDM yang ada di bagian kantor. Setelah data terkumpul. Kemudian diolah dengan menggunakan uji chi square dengan tingkat kepercayaan 95\% (alpha $=5 \%$ ). Dasar pengambilan keputusan dengan ketentuan jika nilai $\mathrm{p}$ $<$ a maka Ho ditolak yang dapat disimpulkan bahwa terdapat hubungan antara variabel independent dengan dependent.

\section{HASIL}

Tabel 1. Distribusi Karakteristik Responden Berdasarakan Lama Kerja dan Masa Kerja di Rumah Sakit Grandmed Lubuk Pakam Tahun 2019

\begin{tabular}{|c|c|c|c|}
\hline No & Karakteristik & f & $\%$ \\
\hline \multirow[t]{3}{*}{1} & Lama Kerja & & \\
\hline & $8 \mathrm{Jam}$ & 36 & 100,0 \\
\hline & Total & 36 & 100,0 \\
\hline \multirow[t]{5}{*}{2} & Masa Kerja & & \\
\hline & 1-4 Tahun & 36 & 100,0 \\
\hline & 5-8 Tahun & - & - \\
\hline & 9-12 Tahun & - & - \\
\hline & Total & 36 & 100,0 \\
\hline
\end{tabular}

Tabel 1 menunjukkan bahwa dari 36 orang pekerja terdapat 36 orang $(100,0 \%)$ yang bekerja 8 jam dalam sehari dengan masa kerja 1-4 tahun.

Tabel 2. Distribusi Responden Berdasarakan Lama Penggunaan Komputer di Rumah Sakit Grandmed Lubuk Pakam Tahun 2019

\begin{tabular}{clrr}
\hline No. & $\begin{array}{c}\text { Lama } \\
\text { Penggunaan } \\
\text { Komputer }\end{array}$ & \multicolumn{1}{l}{$\mathbf{f}$} & \multicolumn{1}{c}{} \\
\hline 1 & Ringan & 5 & 13,9 \\
2 & Sedang & 20 & 55,6 \\
3 & Berat & 11 & 30,6 \\
\hline & Total & $\mathbf{3 6}$ & $\mathbf{1 0 0 , 0}$ \\
\hline
\end{tabular}

Tabel 2 menunjukkan bahwa mayoritas lama penggunaan komputer pada responden berada pada ketegori sedag yaitu sebanyak 20 orang $(55,6 \%)$.

Tabel 3. Distribusi Responden Berdasarakan Kejadian Computer Vision Syndrome di Rumah Sakit Grandmed Lubuk Pakam Tahun 2019

\begin{tabular}{cccc}
\hline No & $\begin{array}{c}\text { Kejadian } \\
\text { Computer } \\
\text { Vision } \\
\text { Syndrome }\end{array}$ & f & \% \\
\hline 1 & $\begin{array}{c}\text { Tidak } \\
\text { Terjadi } \\
\text { CVS }\end{array}$ & 10 & 27,8 \\
2 & $\begin{array}{c}\text { Terjadi } \\
\text { CVS }\end{array}$ & 26 & 72,2 \\
\hline & Total & $\mathbf{3 6}$ & $\mathbf{1 0 0 , 0}$ \\
\hline
\end{tabular}

Dari tabel 3 dapat diketahui bahwa sebagian besar responden tidak mengalami CVS yaitu sebanyak 26 oarng $(72,2 \%)$.

Tabel 4. Hubungan Lama Penggunaan Komputer Dengan Kejadian Computer

Vision Syndrome di Rumah Sakit Grandmed Lubuk Pakam Tahun 2019

\begin{tabular}{|c|c|c|c|c|c|c|c|}
\hline \multicolumn{7}{|c|}{ Kejadian Computer Vision Syndrome } & \multirow{2}{*}{$\begin{array}{c}p- \\
\text { Valu } \\
e \\
\end{array}$} \\
\hline \multirow{2}{*}{$\begin{array}{c}\text { Lama } \\
\text { Pengguna } \\
\text { an } \\
\text { Komputer }\end{array}$} & \multicolumn{2}{|c|}{$\begin{array}{c}\text { Tidak } \\
\text { Terjadi }\end{array}$} & \multicolumn{2}{|c|}{ Terjadi } & \multicolumn{2}{|c|}{ Total } & \\
\hline & $\mathrm{n}$ & $\%$ & $n$ & $\%$ & $\mathrm{n}$ & $\%$ & \\
\hline Ringan & 4 & 11,1 & 1 & 2,8 & 5 & 13,9 & \\
\hline Sedang & 6 & 16,7 & 14 & 38,9 & 20 & 55,6 & \\
\hline Berat & 0 & 0,0 & 11 & 30,6 & 11 & 30,6 & 0,004 \\
\hline Total & 10 & 27,8 & 26 & 72,2 & 36 & 100 & \\
\hline
\end{tabular}

Tabel 4 menjelaskan bahwa berdasarkan hasil analisis diperoleh nilai $\mathrm{p}=0,004<\mathrm{a}=0,05$ yang artinya ada Hubungan Lama Penggunaan komputer 
dengan kejadian computer vision syndrome.

\section{PEMBAHASAN}

Berdasarkan hasil yang didapat peneliti diketahui bahwa Lama Penggunaan Komputer Pada Pegawai Kantor BPJS kesehatan di Rumah Sakit Grandmed Lubuk Pakam berada pada kategori ringan sebesar 13,9\%, kategori sedang sebesar $55,6 \%$ dan kategori berat sebesar $30,6 \%$ (Tabel 2). Lamanya interaksi pekerja di depan komputer tanpa diselingi dengan aktivitas lain dapat menurunkan kemampuan akomodasi mata sehingga akan memperberat gejala CVS pada pekerja.

Tabel 3 menunjukkan bahwa distribusi frekuensi dan persentase responden diketahui bahwa sebanyak 10 orang $(27,8 \%)$ yang tidak mengalami CVS dan sebanyak 26 orang $(72,2 \%)$ mengalami CVS. Hasil ini lebih tinggi dari prevalensi CVS pada karyawan sebuah Universitas di Malaysia yaitu sebesar 68,1\%. Keluhan CVS yang paling banyak dialami adalah mata tegang/ pegal (asthenopia) dan nyeri pada leher/ bahu/ punggung, masingmasing sebesar 73,9\%. Sedangkan, keluhan CVS yang paling sedikit dialami adalah mata kering/ berpasir, yaitu sebesar 23,2\% (Anggraini, 2013).

Berdasarkan hasil uji statistic dengan menggunakan uji Chi Square menunjukkan bahwa p.value $(0,004) \leq$ a $(0,05)$, yang berarti ada hubungan lama penggunaan komputer dengan kejadian computer vision syndrome Pada Pegawai kantor BPJS Kesehatan di Rumah Sakit Grandmed. Berdasarkan hasil analisis oleh (Jonge, 2017) dengan menggunakan uji statistik chi-square disimpulkan bahwa adanya hubungan antara lama penggunaan komputer dengan kejadian CVS pada siswa jurusan TKJ di SMK I Tahuna Kabupaten Sangihe. Dengan menggunakan uji chisquare menyatakan bahwa diperoleh $P$ Value 0,000 . Hal ini berarti nilai $\rho$ lebih kecil dari a $(0,05)$, sehingga dikatakan bahwa Ha diterima yang berarti bahwa terdapat hubungan antara lama penggunaan komputer dengankejadian Computer Vision Syndrome pada Siswa Jurusan Teknik Komputer Dan Jaringan Di SMK 1 Tahuna Kabupaten Sangihe tahun 2017.

Penelitian yang terkait dengan ini, yaitu penelitan yang dilakukan Afifah tahun 2014 didapati terdapat hubungan lama penggunaan komputer dengan keluhan subjektif Computer Vision Syndrome. Durasi penggunaan $>6$ jam lebih besar mengalami keluhan subjektif CVS dibandingkan pengguna komputer dengan durasi $\leq 6$ jam. penggunaan $>$ 6 jam yaitu $69 \%$, sedangkan proporsi penggunaan $\leq 6$ jam yaitu $36 \%$. Hal ini berarti penggunaan komputer dengan durasi penggunaan $>6$ jam memiliki peluang lebih besar mengalami keluhan subjektif CVS dibandingkan dengan durasi penggunaan $\leq 6$ jam.

\section{KESIMPULAN}

yaitu:

Kesimpulan pada penelitian ini

a. Lama penggunaan komputer pada pegawai kantor berada pada kategori sedang $(55,6 \%)$.

b. Sebagian besar pegawai kantor mengalami computer vision syndrome $(72,2 \%)$.

c. Terdapat hubungan lama penggunaan komputer dengan kejadian computer vision syndrome 
$(p=0,004)$.

\section{DAFTAR PUSTAKA}

Afifah A. (2014). Analisis faktor risiko keluhan subjektif computer vision syndrome pada pegawai Bank Negara Indonesia cabang Universitas Indonesia, direktorat kemahasiswaan, dan pengembangan \& pelayanan sistem informasi. Depok: Fakultas Kesehatan Masyarakat Universitas Indonesia. Retrieved from https://www.google.co.id/url?sa =t \&rct $=j \& q=\& e s r c=s \&$ source $=$ web\&c $\mathrm{d}=1 \&$ ved $=2$ ahUKEwjuxpjM7t_oAh UjguYKHU3WCoYQFjAAegQIBRAB\& url=http $\% 3 A \% 2 F \% 2 F l i b . u i . a c . i d \%$ 2Fnaskahringkas\%2F201604\%2FS55437-

Afrini\%2520Nurul\%2520Afifah\&us $\mathrm{g}=$ AOvVaw1X6p0xngZzDz_czabne $\mathrm{AAH}$

Anggraini, Y. (2013). Faktor-Faktor yang Berhubungan Dengan Terjadinya Keluhan Computer Vision Syndrome (CVS) pada Operator Komputer PT. Bank Kalbar Kantor Pusat. Fakultas Kedokteran Universitas Tanjungpura Pontianak.

Akinbinu TR, Mashalla YJ. (2014). Knowledge of computer vision syndrome among computer users in the workplace in Abuja, Nigeria. J Physiol Pathophysiol. 4(4):5863. Retrivied from Izquierdo, N.J. (2016). Computer Vision Syndrome. Retrivied from http://emedicine.medscape.com/a rticle/1229858-overview
Jonge, D, V., (2018). Analisis Hubungan Lama Interaksi Komputer Terhadap Terjadinya Gejala Computer Vision Syndrome Pada Mahasiswa Jurusan Keperawatan Universitas Muhammadiyah Surakarta. Jurnal Keperawatan Universitas Sam Ratulangi 6 (1):2

Sugiyono. (2011). Statistik untuk Penelitian, CV. ALFABETA, Bandung.

Sugiyono. 2017. MetodologiPenelitian Kuantitatif, Kualitatif, dan R\&D. CV. ALFABETA, Bandung.

Valentina, D.C.D., (2018). Computer Vision Syndrome (CVS) Dan Faktor - Faktor Yang Mempengaruhinya Pada Mahsasiswa Jurusan IImu Komputer Fakultas Matematika Dan Ilmu Pengetahuan Alam Universitas Lampung [Skripsi]. Lampung: Fakultas Kedokteran Universitas Lampung. 